\title{
Impact of chronic ethanol intake of rat mothers on the seizure susceptibility of their immature male offspring
}

\author{
Vladimir Riljak, Dana Maresova, Katerina Jandova, Jana Bortelova and Jaroslav Pokorny \\ Institute of Physiology, First Faculty of Medicine, Charles University in Prague, Czech Republic
}

\begin{abstract}
The aim of present study was to examine the impact of prenatal ethanol exposure on seizure susceptibility of the offspring. Pregnant Wistar rats were compelled to drink either $10 \%$ or $20 \%$ ethanol solution, as the only drinking fluid since conception up to the weaning of their offspring at the age of 28 days. Pregnant and nursing rats of the control group drank water. Electrophysiological experiments (repeated electrical stimulation and analysis of cortical afterdischarges duration) were than performed on their immature offspring. Rat pups were tested on postnatal day 18, 25, and 35 . Shortening of afterdischarges duration was observed in 18-day-old animals (mothers drank 20\% ethanol) when compared with age matched controls and failure of post-ictal depression phenomenon was found in 25- and 35-day-old animals. Our findings signalize that ethanol exposure during pregnancy influences seizure susceptibility by acting on excitatory/inhibitory brain systems and this effect is dose- and age-dependent.
\end{abstract}

Key words: Ethanol - Evoked potentials - Seizure - Development - Rat

\section{Introduction}

Long-term ethanol intake affects the central nervous system of living organisms by many different ways. Chronic ethanol consumption by pregnant women results in offspring growth retardation, abnormal brain development, impaired brain function and dysmorphology, termed as foetal alcohol syndrome (Abel 1984). Ethanol interacts with nearly all described neurotransmitters, while most important for its behavioural consequences is the interaction with excitatory and inhibitory ones (Brailowsky and Garcia 1999). Ethanol directly influences the GABA-ergic system as well as N-methyl-D-aspartate receptors (Fadda and Rossetti 1998; Woodward 2000). Together with mentioned neurotransmitters systems, important role in the ethanol intake sequels plays the monoaminergic system (Cowen and Lawrence 2006) and probably dopamine, whereas 5-hydroxytryptamine seems to be involved in reinforcing effects of ethanol (Vengeliene et al. 2008).

Correspondence to: Vladimir Riljak, Institute of Physiology, First Faculty of Medicine Charles University in Prague, Albertov 5, 12800 Prague 2, Czech Republic

E-mail: vladimir.riljak@lf1.cuni.cz
Consequently, functional changes of the serotoninergic system probably mediate addiction-prone behavior (Barr et al. 2003; Oreland et al. 2004). There is evidence, that children suffering from foetal alcohol syndrome are seizure-prone (Abel 1984) and such increased susceptibility mediated by ethanol exposure was demonstrated in differently designed animal experiments (Berman et al. 1992; Bonthius et al. 2001). On the other hand, Abel and co-workers demonstrated that prenatal alcohol exposure attenuates pentylenetetrazol-induced seizure (Abel et al. 1993) and such, at least partial, anticonvulsant effect of ethanol was reported by Kim and co-workers (1991). For all above mentioned facts we decided to test the effects of chronic ethanol consumption during pregnancy and lactation period on offspring seizure susceptibility. We used cortical epileptic afterdischarges (ADs) as a model (Mares et al. 1982-1983; Maresova et al. 2010; Riljak et al. 2011) and rat pups aged 18, 25 and 35 days were tested (PD18, 25, 35). The age groups we chose covered the all early developmental stages of the brain: 18-day-old rats (in humans is parallel to early school age), 25-day-old rats (parallel to the beginning of sexual maturation) and 35day-old (parallel to young adulthood). We hypothesized, that chronic ethanol consumption influences the duration of $\mathrm{ADs}$ and this effect would be age-dependent. 


\section{Materials and Methods}

\section{Animals and ethanol treatment}

Pregnant Wistar rats of the experimental group were compelled to drink either 10\% (Group ET10) or $20 \%$ ethanol solution (Group ET20) (as the only drinking fluid) since conception up to the weaning of their offspring at the age of 28 days. Pregnant rats of the control group drank water. Since the 29th day the offspring were separated from their mothers. Electrophysiological experiments (ADs) were than performed on rat pups aged 18,25, and 35 days. The day of birth was counted as 0 . Animals were housed at a constant temperature $\left(23 \pm 1^{\circ} \mathrm{C}\right)$ and relative humidity $(60 \%)$ with a fixed $12 \mathrm{~h}$ light/dark cycle (with lights on at 07:00) and fed (or their mothers) with food and water or ethanol solution ad libitum. On the testing day animals were transported into the experimental room, weighed (weight was used as a marker of somatic development), marked and assigned into particular experimental groups. All tests were performed between 9 a.m. and 2 p.m. There were at least 10 rats pups in each experimental group. All experiments were carried out in accordance with the European Communities Council Directive (86/609/EEC) and in agreement with the guidelines of the Animal Protection Law of the Czech Republic.

\section{Electrophysiology}

Surgical preparation took place at the day of recording. Under deep anaesthesia six silver electrodes were implanted epidurally through the cranium: two stimulation electrodes (right sensorimotor cortex), three registration electrodes (left sensorimotor cortex, left and right visual cortex) and reference electrode (placed into nasal bone). Recording and other experimental manipulations were carried out after the recovery of righting and suckling reflexes (i.e. approximately 15 min after the surgery), then the cortical afterdischarges were elicited by stimulation of the right sensorimotor cortex. We used constant current stimulation (bipolar pulses - pulse period $1 \mathrm{~ms}$; duration of stimulation $15 \mathrm{~s}$; frequency $8 \mathrm{~Hz}$;

Table 1. Comparison of body weight of experimental animals (18-, 25-, and 35-day-old) before (control) and after ethanol treatment $(10 \%, 20 \%)$

\begin{tabular}{lccc}
\hline \multirow{2}{*}{$\begin{array}{l}\text { Age } \\
\text { (days) }\end{array}$} & \multirow{3}{*}{ Control } & \multicolumn{2}{c}{ Eodhanol (\%) } \\
\cline { 2 - 4 } & & 10 & 20 \\
\hline 18 & $40.41 \pm 3.64$ & $39.58 \pm 3.66$ & $43.00 \pm 3.5$ \\
25 & $51.63 \pm 8.3$ & $65.73 \pm 7.84^{*}$ & $59.30 \pm 4.31^{\star}$ \\
35 & $120.61 \pm 8.77$ & $131.08 \pm 4.96^{*}$ & $125.55 \pm 10.42$ \\
\hline
\end{tabular}

* significantly different from control, $p<0.05$. intensity 3-5 mA, which is sufficient for ADs eliciting). The basic stimulation intensity level was set at $3 \mathrm{~mA}$. In case of no response, another stimulation of $4 \mathrm{~mA}$ was used 5 min after the first stimulation. The process was similarly repeated with $5 \mathrm{~mA}$ stimulation. Finally, if no epileptic graphoelements appeared after the $5 \mathrm{~mA}$ stimulation, the animal was excluded from the experiment. If a distinct response (epileptic graphoelements) was recorded, the stimulation was repeated five times at one-minute intervals (timed from the end of each seizure to the beginning of the next stimulation). The duration of evoked ADs and the shape of evoked graphoelements were recorded. Electrocorticograms (ECoG) were recorded $5 \mathrm{~min}$ before the very first stimulation and during whole stimulation process. The behaviour of rats was marked digitally in the ECoG recording.

\section{Statistics}

Obtained data were analyzed using nonparametric tests. To compare the differences in ADs length in six subsequent stimulations in particular groups, Friedman test followed by Wilcoxon signed rank test were used. To compare the differences between the ethanol-exposed rats and age-matched controls within a given session, Kruskal-Wallis test and the Mann-Whitney test were used. Data is presented as mean \pm SEM.

\section{Results}

\section{Somatic development}

Differences between the ethanol-treated groups and control group in the number of pups in litter and male/female ratio were not observed. Body weight was tested in the day of birth (no differences between the experimental groups) and in day of ECoG experiment. Significantly higher $(p<0.05)$ body weight was found in 25- and 35-day-old animals (group ET10 or ET20) compared to controls. The youngest group did not differ from controls (Table 1).

\section{Electrophysiological study}

Forelimbs movements in the rhythm of stimulation were observed during the stimulation of sensorimotor cortical area. ADs were typically represented by spike- and wave rhythm (Fig. 1). Clonic movements that accompanied elicited afterdischarges were synchronous with sharp ECoG graphoelements. Analysis of ADs duration (Fig. 2) in control animals confirmed previously described phenomenon of post-ictal depression (duration of the $2^{\text {nd }}$ and following two ADs is shorter, compared with the first ADs length) characterized by typical "U-shape curve" in 25- and 35-day-old control 


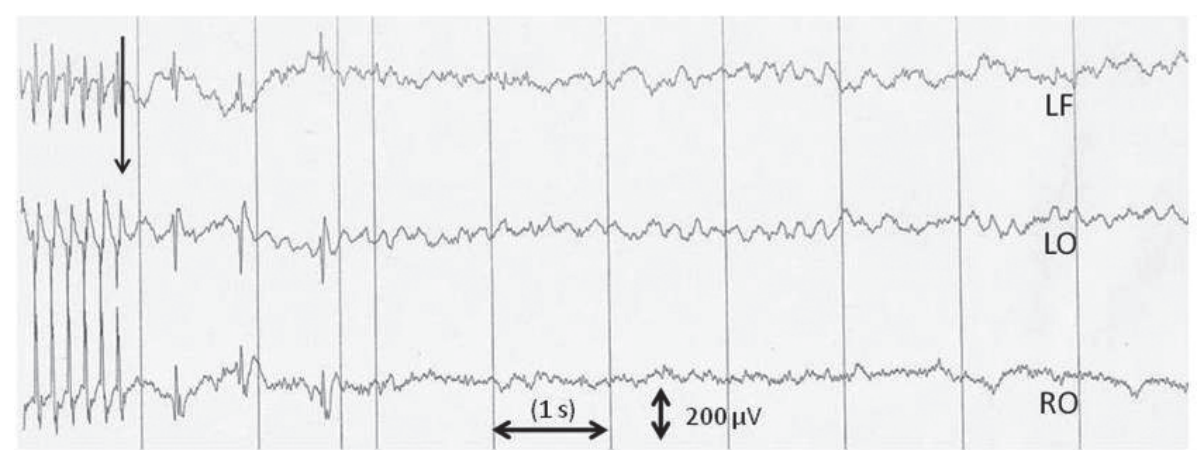

Figure 1. Electrocorticographic recording of a cortical epileptic afterdischarge (ADs) in a 35-day-old rat. Individual leads from top to bottom: left frontal (LF), left occipital (LO) and right occipital (RO) areas, all in reference connection. Time mark is $1 \mathrm{~s}$ and amplitude calibration is $200 \mu \mathrm{V}$. Arrow indicates the end of stimulation.

animals (mother drank water). Such shape is characteristic for our experimental pattern and cannot be fully observed in younger experimental animals, reflecting the immaturity of inhibitory mechanisms in developing brain. 18-day-old offspring of mothers exposed to $20 \%$ ethanol exhibited shortening of ADs after all six stimulations, while reaching statistical significance only after the $5^{\text {th }}$ and $6^{\text {th }}$ stimulation. Lower dose of ethanol did not bring such effect and ADs length was comparable with controls. Certain tendency to decrease ADs duration in 25-day-old animals, their mothers drank higher ethanol dose was outlined (statistical significance was not reached). ADs duration in 25- and 35-day-old experimental groups remained unaffected by their mother's ethanol consumption when compared with age matched controls, but interestingly the complete failure of post-ictal depression phenomenon in 25- and 35-day-old rats was observed. Subsequent stimulation did not bring the shortening of the $2^{\text {nd }}$ and $3^{\text {rd }}$ ADs duration (and even the $4^{\text {th }}$ one in oldest group) found in controls (compared to the $1^{\text {st }}$ one, which serves as baseline) - such changes suggest that inhibitory mechanisms were impaired.

\section{Discussion}

The objective of the present study was to determine whether the chronic ethanol intake by rat mothers influences the seizure susceptibility in their offspring. To prove this we decided to use the method of electrical stimulation and ECoG recording. The experimental pattern of six repeated stimulations with short inter-stimulus interval has been used in our laboratory for many years (Maresova and Mares 1999; Riljak et al. 2010). When developing brain is exposed to ethanol the sequels of such exposition could be expressed as neuronal degeneration, structural and functional disturbances (Sowell et al. 2001; Milotova et al. 2008). Ethanol intake could influence the development of thalamo-cortical connections and impair the somatosensory cortex (al-Rabiai and Miller 1989; Minciacchi et al. 1993; Granato et al. 1995; Miller 1997, 2006). On the other hand, results of some studies indicated anticonvulsant effects of ethanol against generalized tonic-clonic as well as complex partial seizures (Fischer 2005); Mladenovic and coworkers demonstrated the anticonvulsant effect of ethanol on lindane-induced seizures (Mladenovic et al. 2008). Mechanisms underlying ethanol-induced changes of brains microenvironment include: influence of $N$-methyl-D-aspartate receptors system (Chandler et al. 1993), inhibition of neurogenesis (Nixon and Crews 2002) and oxidative stress (Crews and Nixon 2008). All above mentioned mechanisms are very probably involved in changes of cortex excitability as well. We observed shortening of ADs duration in the youngest animals of mothers drinking chronically $20 \%$ ethanol solution, while the lower ethanol concentration didn't bring statistically significant changes. This observation is in sharp contrast with results observed in two older experimental groups where the ADs duration remained unaffected by mothers' ethanol drinking when compared with appropriate controls. The oldest group was tested at PD35 so the last exposure to ethanol came at PD28 - probably the period was sufficient for recovery, at least partial, of the excitatory/inhibitory brain systems. It would be interesting to test even older offspring to confirm whether ethanol is capable to influence the ADs duration in the long-term. Second interesting finding is the complete failure of post-ictal depression in 25- and 35-day-old rats. Subsequent stimulation did not bring the shortening of the $2^{\text {nd }}, 3^{\text {rd }}$ and $4^{\text {th }}$ ADs (compared to the $1^{\text {st }}$ one, which serves as baseline) - such changes suggest that inhibitory mechanisms were impaired. Similar results were found in 25-day-old animals. Despite they were exposed to ethanol during whole life, outlined tendency for shortening ADs length after two very last stimulations did not reach statistical 
significance. Yet, again complete failure of post-ictal depression phenomenon, that was partially expressed in control group indicates, that maintenance of excitatory/inhibitory

\section{8-day-old}

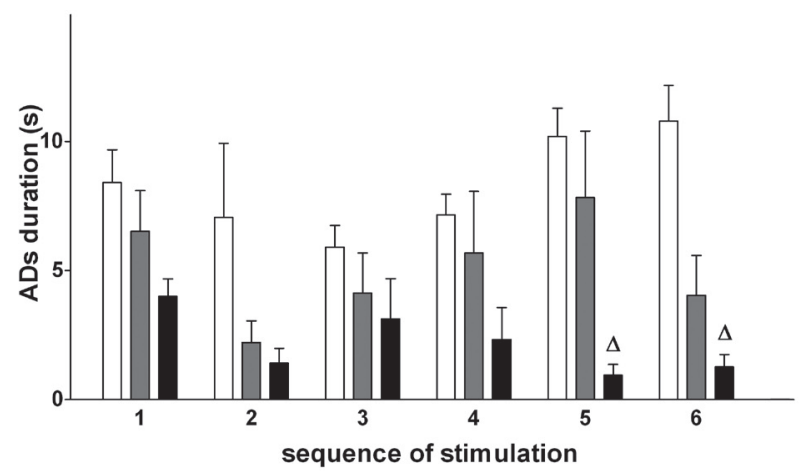

25-day-old

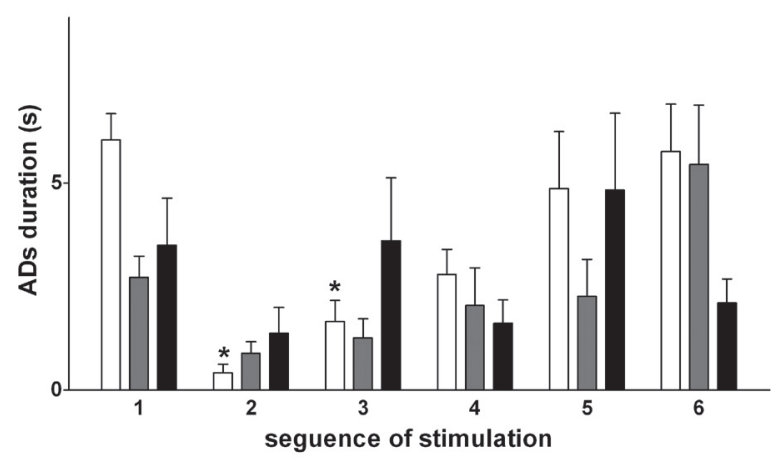

35-day-old

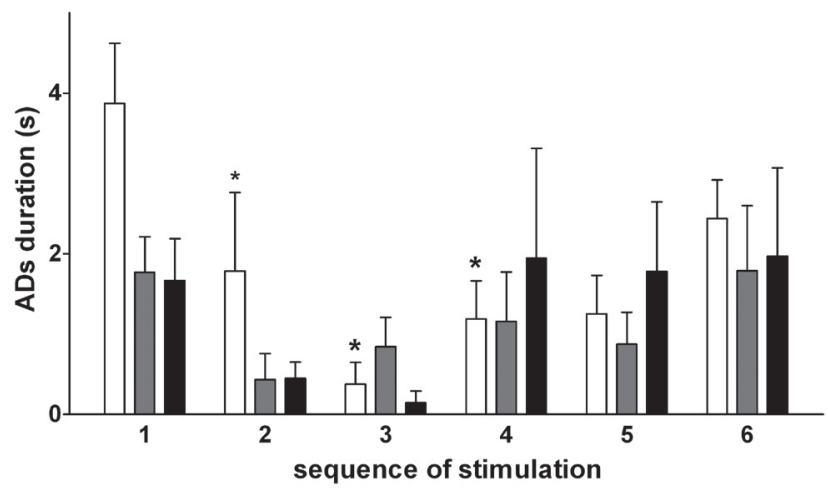

Figure 2. Duration of six subsequent cortical ADs in 18-, 25- and 35-day-old rats. White columns, control; grey columns, $10 \%$ ethanol; black columns, 20\% ethanol. Asterisks indicate differences significant at $p<0.05$ between the particular repetition of stimulation and the duration of the very first ADs (baseline) of the same animals. Symbols $\Delta$ indicate results significant at $p<0.05$ between the control group and ethanol exposed animals (within particular stimulation). The error bars in graph indicates the standard error of the mean (SEM). equilibrium was imbalanced. Mentioned failure of post-ictal depression was observed in both ethanol groups - so even $10 \%$ ethanol solution drank by mothers possessed the ability to influence seizure susceptibility of their offspring. Together with seizures susceptibility we observed an increase of body weight in 25 - and 35 -day-old rats. It was very probably elicited by increased energetic intake (ethanol solution $v s$. water in controls). Such effect is more pronounced in two older experimental groups because they are able to reach ethanol solution, while the nutrition of 18-day-old rats is the mother's milk only. This could explain, at least partially, age-related differences in ethanol-induced changes of senzorimotor cortex excitability.

In conclusion, in our experimental pattern of repeated electrical stimulation chronic ethanol intake influenced the seizure susceptibility of 18-day-animals in the negative way; its effect seems to be rather anticonvulsive, while in 25- and 35-day-old animals the observed failure of post-ictal depression signalizes the proconvulsive ethanol properties. These properties were not dose-dependent. We demonstrated that ethanol intake during pregnancy influences the seizures susceptibility of mother's offspring age-dependently.

Acknowledgment. This work was supported by grants: GACR 305/09/P136 and MSM 0021620816.

\section{References}

Abel E. L. (1984): Prenatal effects of alcohol. Drug Alcohol Depend. $14,1-10$ http://dx.doi.org/10.1016/0376-8716(84)90012-7

Abel E. L., Berman R. F., Church M. W. (1993): Prenatal alcohol exposure attenuates pentylenetetrazol-induced convulsions in rats. Alcohol 10, 155-157 http://dx.doi.org/10.1016/0741-8329(93)90096-7

al-Rabiai S., Miller M. W. (1989): Effect of prenatal exposure to ethanol on theultrastructure of layer $\mathrm{V}$ of mature rat somatosensory cortex. J. Neurocytol. 18, 711-729 http://dx.doi.org/10.1007/BF01187226

Barr C. S., Newman T. K., Becker M. L., Champoux M., Lesch K. P., Suomi S. J., Goldman D., Higley J. D. (2003): Serotonin transporter gene variation is associated with alcohol sensitivity in rhesus macaques exposed to early-life stress. Alcohol. Clin. Exp. Res. 27, 812-817 http://dx.doi.org/10.1097/01.ALC.0000067976.62827.ED

Berman R. F., Beare D. J., Church M. W., Abel E. L. (1992): Audiogenic seizure susceptibility and auditory brainstem responses in rats prenatally exposed to alcohol. Alcohol. Clin. Exp. Res. 16, 490-498

http://dx.doi.org/10.1111/j.1530-0277.1992.tb01406.x

Bonthius D. J., Pantazis N. J., Karacay B., Bonthius N. E., Taggard D. A., Lothman E. W. (2001): Alcohol exposure during the brain growth spurt promotes hippocampal seizures, rapid kindling, and spreading depression. Alcohol. Clin. Exp. Res. 25, 734-745 http://dx.doi.org/10.1111/j.1530-0277.2001.tb02274.x 
Brailowsky S., García O. (1999): Ethanol, GABA and epilepsy. Arch. Med. Res. 30, 3-9 http://dx.doi.org/10.1016/S0188-0128(98)00013-X

Chandler L. J., Newsom H., Sumners C., Crews F. (1993): Chronic ethanol exposure potentiates NMDA excitotoxicity in cerebral cortical neurons. J. Neurochem. 60, 1578-1581 http://dx.doi.org/10.1111/j.1471-4159.1993.tb03326.x

Cowen M. S., Lawrence A. J. (2006): Alcoholism and neuropeptides: an update. CNS Neurol. Disord. Drug Targets 5, 233-239 http://dx.doi.org/10.2174/187152706776359646

Crews F. T., Nixon K. (2008): Mechanisms of neurodegeneration and regeneration in alcoholism. Alcohol Alcohol. 44, 115-127 http://dx.doi.org/10.1093/alcalc/agn079

Fadda F., Rossetti Z. L. (1998): Chronic ethanol consumption: from neuroadaptation to neurodegeneration. Prog. Neurobiol. 56, 385-431 http://dx.doi.org/10.1016/S0301-0082(98)00032-X

Fischer W. (2005): Influence of ethanol on the threshold for electroshock-induced seizures and electrically-evoked hippocampal afterdischarges. J. Neural Transm.112, 1149-1163 http://dx.doi.org/10.1007/s00702-004-0266-0

Granato A., Santarelli M., Sbriccoli A., Minciacchi D. (1995): Multifaceted alterations of the thalamo-cortico-thalamic loop in adult rats prenatally exposed to ethanol. Anat. Embryol. (Berl.) 191, 11-23 http://dx.doi.org/10.1007/BF00215293

Kim C. K., Weinberg J., Pinel J. P. J. (1991): Effects of prenatal ethanol exposure on susceptibility to convulsions and response to the anticonvulsant effects of ethanol in rats. Alcohol. Clin. Exp. Res. 15, 337-346

Mares P., Rokyta R., Trojan S. (1982 -1983): Epileptic seizures during ontogenesis in the rat. J. Physiol. (Paris) 78, 863-864

Maresová D., Mares P. (1999): Dizocilpine pretreatment suppresses the action of hypoxia on hippocampal epileptic afterdischarges in immature rats. Physiol. Res. 48, 389-394

Maresova D., Riljak V., Mares J. (2010): Melatonin modulates hypoxia-induced changes of rat brain excitability. Gen. Physiol. Biophys. 29, 67-71 http://dx.doi.org/10.4149/gpb_2010_01_71

Miller M. W. (1997): Effects of prenatal exposure to ethanol on callosal projection neurons in rat somatosensory cortex. Brain Res. 766, 121-128 http://dx.doi.org/10.1016/S0006-8993(97)00533-7
Miller M. W. (2006): Effect of prenatal exposure to ethanol on glutamate and GABA immunoreactivity in macaque somatosensory and motor cortices: critical timing of exposure. Neuroscience 138, $97-107$ http://dx.doi.org/10.1016/j.neuroscience.2005.10.060

Milotová M., Riljak V., Jandová K., Bortelová J., Maresová D., Pokorný J., Langmeier M. (2008): Changes of hippocampal neurons after perinatal exposure to ethanol. Physiol. Res. 57, 275-282

Minciacchi D., Granato A., Santarelli M., Sbriccoli A. (1993): Modifications of thalamo-cortical circuitry in rats prenatally exposed to ethanol. Neuroreport 4, 415-418 http://dx.doi.org/10.1097/00001756-199304000-00019

Mladenović D., Hrncić D., Radosavljević T., Vucević D., Djurić D., Rasić-Marković A., Macut D., Susić V., Sćepanović L., Stanojlović O. (2008): Dose-dependent anticonvulsive effect of ethanol on lindane-induced seizures in rats. Can. J. Physiol. Pharmacol. 86, 148-152

Nixon K., Crews F. T. (2002): Binge ethanol exposure decreases neurogenesis in adult rat hippocampus. J. Neurochem. 83, 1087-1093 http://dx.doi.org/10.1046/j.1471-4159.2002.01214.x

Oreland L., Hallman J., Damberg M. (2004): Platelet MAO and personality--function and dysfunction. Curr. Med. Chem. 11, 2007-2016

Riljak V., Maresova D., Pokorny J. (2010): Nicotine effects on rat seizures susceptibility and hippocampal neuronal degeneration. Neuro. Endocrinol. Lett. 31, 792-795

Riljak V., Marešová D., Pokorný J. (2011): Nicotine reduces mortality of developing rats exposed to high-altitude hypoxia and partially suppresses the duration of cortical epileptic afterdischarges. Gen. Physiol. Biophys. 30, 350-355

http://dx.doi.org/10.4149/gpb_2011_04_350

Sowell E. R., Mattson S. N., Thompson P. M., Jernigan T. L., Riley E. P., Toga A. W. (2001): Mapping callosal morphology and cognitive correlates: effects of heavy prenatal alcohol exposure. Neurology 57, 235-244

Vengeliene V., Bilbao A., Molander A., Spanagel R. (2008): Neuropharmacology of alcohol addiction. Br. J. Pharmacol. 154, 299-315 http://dx.doi.org/10.1038/bjp.2008.30

Woodward J. J. (2000): Ethanol and NMDA receptor signaling. Crit. Rev. Neurobiol. 14, 69-89

Received: December 5, 2011

Final version accepted: January 12, 2012 